Pirineos, 147-148: 97 a 113, JACA; 1996

\title{
ALTERACIONES POR EL FUEGO EN LA CORDILLERA DE LA COSTA DE CHILE MEDITERRANEO. ANTECEDENTES EN UN PARQUE NACIONAL*
}

\author{
Víctor Quintanilla PÉrez $\left(^{*}\right)$ \\ (*) Departamento Ingeniería Geográfica. Universidad de Santingo de Chile.
}

\begin{abstract}
RESUMEN: Se describe la cadena del Cerro de la Campana, cuyos recursos naturales han determinado la creación en la zona de un Parque Nacional. Los aspectos más interesantes de la zona se relacionan con la existencia en la misma de bosques subtropicales relictos, así como de bosquetes de palmeras en los que la familia palmáceas alcanza su limite extremo meridional. Por otra parte, la variedad ecológica del área es muy elevada, al igual que su riqueza específica, puesto que alberga numerosas especies de vertebrados, invertebrados y plantas. Muchas especies encuentran aquí su límite meridional absoluto. Sin embargo la zona se encuentra amenazada por la presión humana, especialmente en la forma de incendios forestales y tala masiva, a pesar de que muchas comunidades naturales parecen estar adaptadas a los incendios repetidos. En el trabajo se analizan las consecuencias de estas amenazas y se sugieren medidas encaminadas a la protección del paraje.
\end{abstract}

ABSTRACT: The Cerro de la Campana range, in the central part of Chile, is described. The area has several important features, and parts of it have been declared as National Park. Besides the high taxonomic and ecologic diversity, both in animals and in plants, it las the southernmost forests of palm trees, as well as many other subtropical residual forests. Many species reach here the extreme south limit. But the ecosystems of the area are endangered and most of them have been decreasing or even vanishing in the past because of the human pressure. The main dangers come from fire and from slash cutting, although many natural communities there seem to be adapted to periodic burns. The consequences of these dangers and some protective measures are discussed.

Keywords: Chile Andes, Coastal Chile Range, Cerro de la Campana, National Parks, palm trees, forest fires, biodiversity, nature protection.

* Proyecto FONDECYT n" 1950313. 


\section{El área de estudio}

El cordón del Cerro La Campana se localiza en la cordillera de la costa de Chile central y su cumbre más alta alcanza a los 1.930 m.s.n.m. Las coordenadas geográficás de esta montaña aproximadamente corresponden a los $32^{\circ}$ $51^{\prime \prime}$ sur y $70^{\circ} 59^{\prime \prime}$ a $71^{\circ} 15^{\prime \prime}$ oeste. La cordillera de la costa en este sector del país se presenta fuertemente meteorizada y se levanta con gran energía y aspecto de muro, alcanzando precisamente en este sector las cumbres más altas de todo el cordón costero del centro del territorio chileno (Cerro El Roble 2222 m, Cerro Las Viscachas 2210 m,Cerro La Campana, 1930 m.) (Figura 1).

Este macizo está integrado en una gran cadena que parte desde el Cerro El Roble (2222 m) hacia el norte empalmando con el cerro El Reloj ( $1.475 \mathrm{~m})$; hacia el sur con el cerro El Duraznillo $(1.722 \mathrm{~m})$ y hacia el oeste con el cerro La Campana $(1930 \mathrm{~m})$. Desde allí el cordón se prolonga hasta el Cerro La Campanita $(1556 \mathrm{~m})$ donde cambia de curso empalmando hacia el norte con el cerro Alto del Barco (1.180 m) y con el cerro Santa Teresa (1025 m) (Figura 2).

\section{CROQUIS DE UBICACION}

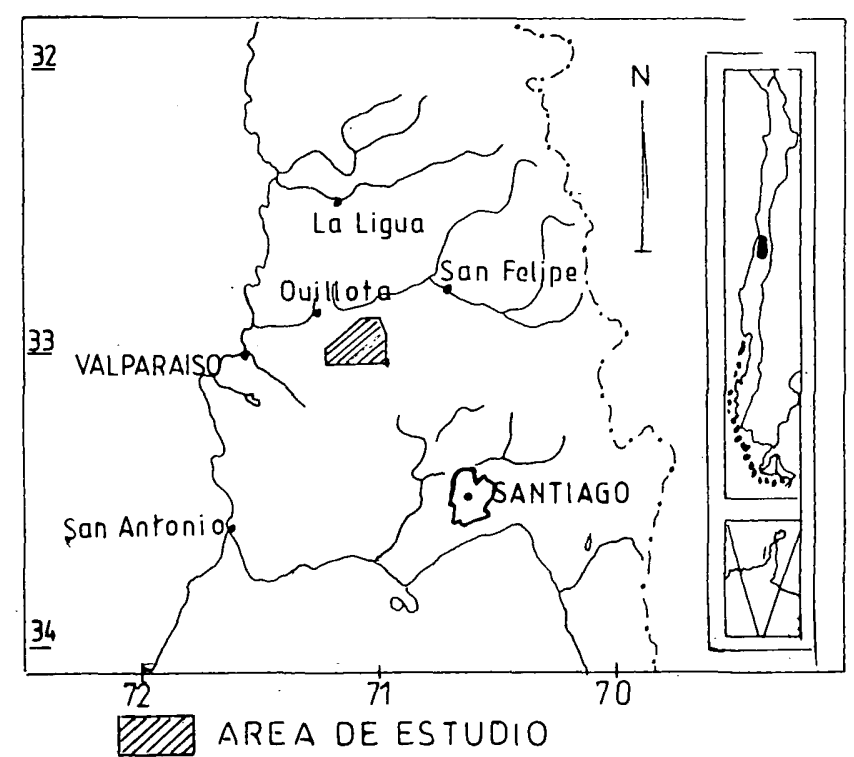

Fig.1. Situación del área de estudio en Chile The situation of the study area 
EFECTOS FUEGO CHILE

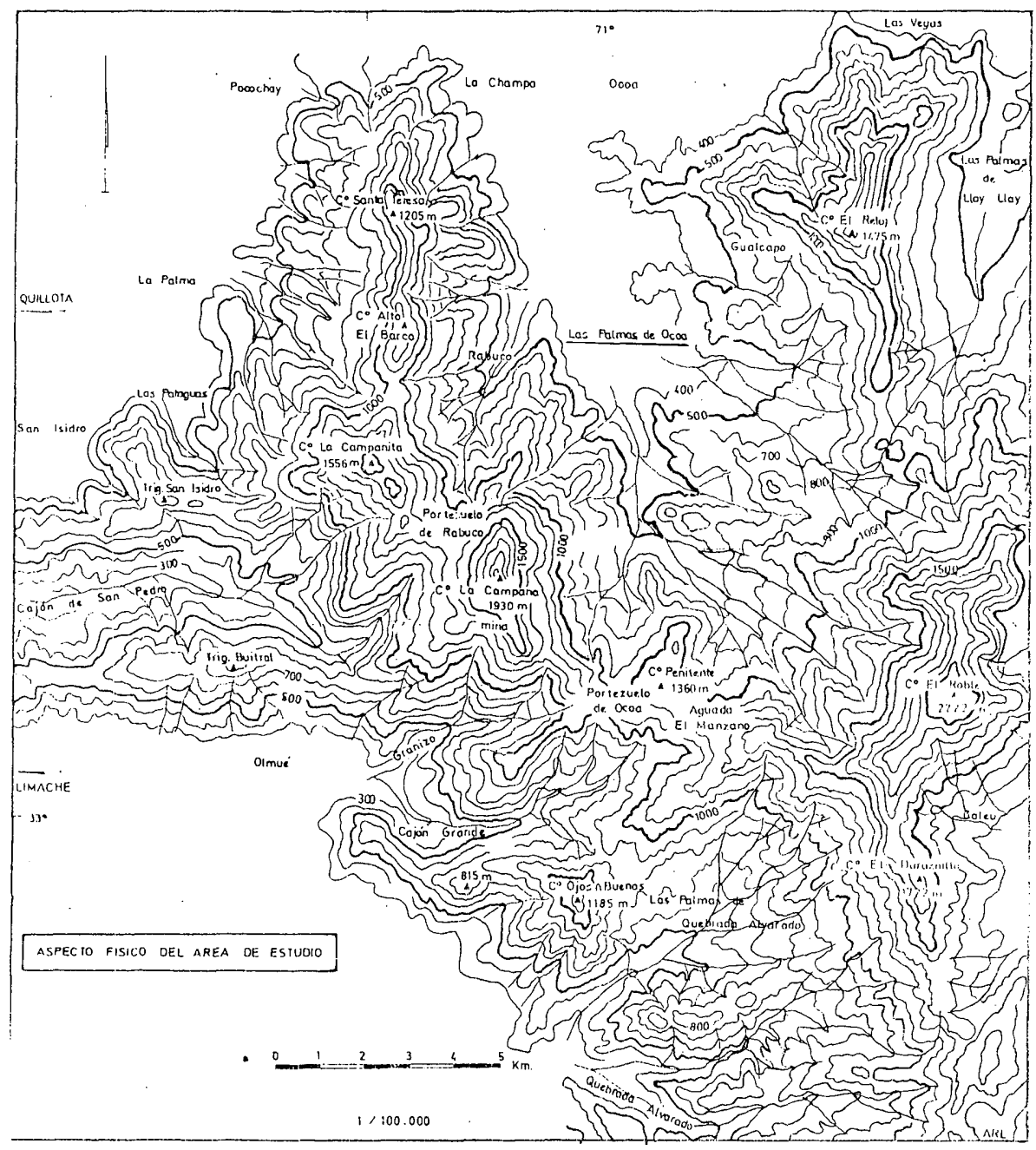

Fig. 2. Topografía del área de estudio Map of the study area 
La región debe su elevación principalmente a la existencia de rocas duras y resistentes,especialmente andesíticas que forman gran parte de la espina dorsal de esta cadena de cerros (THOMAS, 1958). Está constituída por rocas estratificadas volcánicas y sedimentarias cuya edad corresponde al Jurásico Medio, Cretácico Inferior y Cretácico Medio. Existen además rocas intrusivas que al contacto con rocas estratificadas origina una aureola de metamorfismo. Las rocas volcánicas consisten en lavas, tobas, brechas, andesitas y las sedimentarias en limonitas, areniscas y brechas sedimentarias con escasas intercalaciones lenticulares de caliza. En la parte este del área las rocas estratificadas están instruidas por el Batolito de Caley, de composición predominantemente granodiorítica, diorítica y gábrico en la cumbre y faldeos de La Campana. La edad de este cuerpo sería Cretácico Superior, según determinaciones radiométricas efectuadas por el método potasio-argón (THIDY,1979).

En este ambiente físico se localiza el Parque Nacional La Campana que ocupa una superficie aproximada de 8.000 hectáreas.

En cuanto a los elementos del clima éste se encuentra influenciado por la presencia del anticiclón del Pacífico, que durante los meses de invierno se desplaza hacia el norte y se aleja del continente, permitiendo el paso de los sistemas frontales provenientes del océano. El papel inhibidor que juega el anticiclón se expresa en bloqueo, disminución de velocidades y cambios de dirección para las depresiones ciclonales que atraviesan el océano. Por esta razón las influencias ciclonales pierden importancia en primavera y verano hasta llegar a ser nulas completamente. Igualmente la alta nubosidad costera de la región se encuentra asociada a las condiciones anticiclonales generalizadas para la zona en primavera y verano; en cambio, en los meses de otoño e invierno (Abril a Agosto) la nubosidad será producto del avance de centros depresivos acompañados por sus respectivos frentes. Contribuye además a esta alta nubosidad costera la acción de la corriente fría de Humboldt, que la genera durante todo el año. El relieve también coadyuva a fortalecer los sistemas frontales, aumentando la precipitación en las partes altas de las vertientes occidentales (600 a $800 \mathrm{~mm}$ ) y disminuyendo a unos $300 \mathrm{~mm}$ en las vertientes orientales. Además la orografía constituye un obstáculo a la nubosidad costera y a las masas de aire húmedo provenientes del océano y tales fenómenos inciden en una menor radiación solar y temperaturas menos extremas en las vertientes que miran hacia la gran depresión central de Chile, con una nubosidad y humedad menores que influyen en el aumento de la radiación y de las temperaturas (RODRÍGUEZ, 1980).

El clima de esta zona entonces corresponde al tipo mediterráneo con inviernos fríos y húmedos y veranos cálidos y secos (QUINTANILLA, 1974, 1983) 


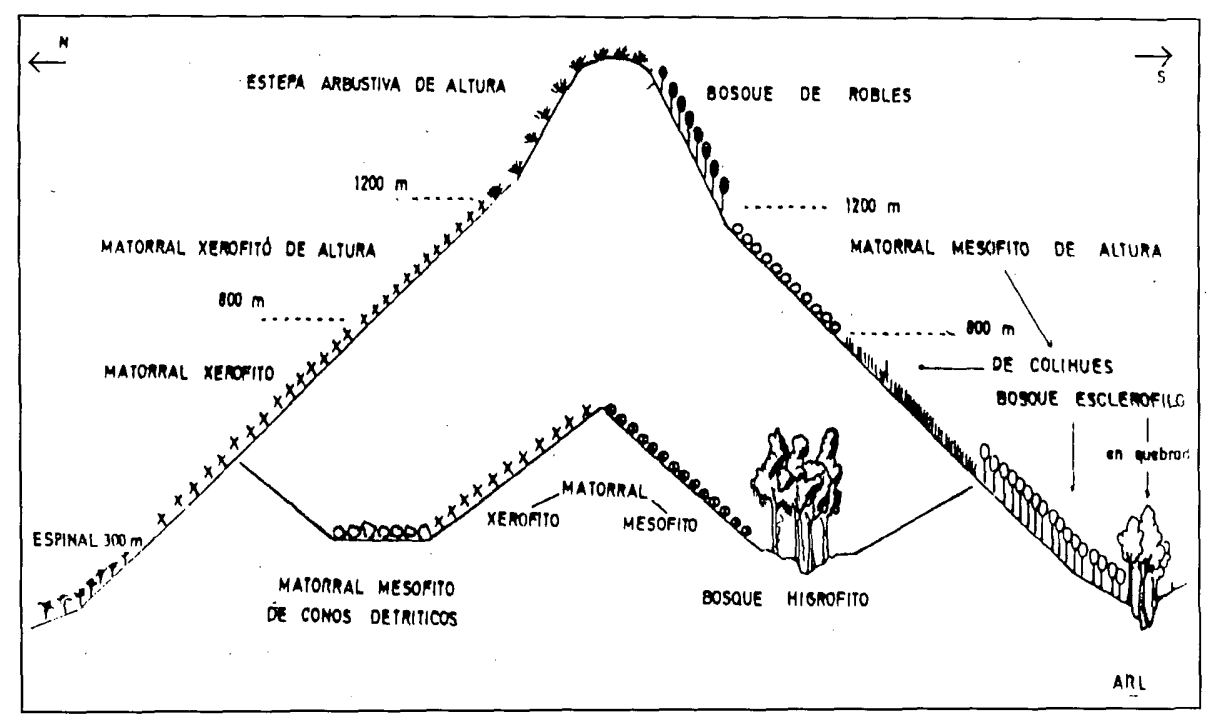

Fig. 3. Disposición de las formaciones vegetales en dos cortes de la cadena montañosa Plant formations along two altitudinal transects

\section{Los rasgos biogeográficos del Parque Nacional La Campana}

El Parque Nacional La Campana fue creado por ley $N^{\circ} 16.699$ el 17 de Octubre de 1967 y está bajo custodia de la Corporación Nacional Forestal (CONAF) de Chile.

Su topografía irregular permite el desarrollo de situaciones ecológicas diversas que albergan una flora y una fauna muy ricas en especies. Desde el punto de vista biogeográfico existe una convergencia florística con elementos de origen templado australes (Nothofngus) y templados septentrionales (Ribes), mediterráneos (Mirtáceas) y tropicales (Palmáceas) (Figura 3.)

Respecto a la fauna, la variedad de situaciones ecológicas del parque determina como para las plantas, una gran diversidad animal en el que se mezclan elementos de muy diverso origen. Esto lo constituye en un lugar de alto interés para el estudio de su fauna.

Entre los artrópodos se encuentran representantes de arácnidos, cuyos elementos más frecuentes son las "arañas albañiles" (Calathotarsus simoni) y las "arañas peludas" (Tryssothele, Grammostola, Paraphysa). Los miriápodos están representados por el "milpiés" (Autostreptus yanezi), "cientopiés" (Hemiscolopendra chilensis) y "escutigeras" (Scutigera sp.). 
Entre los insectos hay elementos característicos de las formaciones forestales del sur de Chile. De estas especies puede mencionarse a coleópteros de suelo (Lathridiidae, Pselaphidae) y de follaje (Cleridae). Las especies más llamativas son la "madre de la culebra" (Ancistrotus cumingi) el coleóptero "la cruz de malta" (Strongilapsis limae), grandes abejas como Caupolicana gayi o Bombus dahlbomii y avispas cazadoras de arañas (Pompilidae). Entre los lepidópteros destacan por su tamaño y colorido la "mariposa del chagual" (Castania psittacus) y la "mariposa plateada" (Argyrophorus argenteus).

Entre los vertebrados se encuentran anfibios cuyas especies más comunes son el "sapo de rulo" (Bufo chilensis) y el "sapo popeye" (Eupssophus nodosus). Entre los reptiles se destaca un gran número de lagartijas (Liolaemus), además de las culebras de cola corta (Tachymenis chilensis) y de cola larga (Alsophis chamissonis).

Las aves están muy bien representadas en el área con un número aproximado de 40 especies, dentro de las cuales las más importantes son: águila (Geranoaetus melanoleucus) torcaza (Columba araucana), chuncho (Glaucidium nanum) y un gran número de Passeriformes tales como la "turca" (Pteroptochos megapodius), el "rayadito" (Aphrastura spinicauda) y el "cometocino" (Phrygilus gayi), Mención especial merece la presencia del colilarga del sur" (Sylviorthorhynchus desmurrii) y el "comesebo" (Pygarrhicas albogularis), aves propias de los bosques del sur del país que tienen en el parque su límite norte de distribución.

Además, es posible encontrar el cóndor (Vultur gryphus) y el picaflor más grande del mundo (Patagonas gigas).

La fauna de mamíferos es rica en roedores (Octodon, Akodon, Abracoma). También se encuentran el zorro rojo o culpeo (Dusicyon culpeus), el quique (Grison cuya), el chingue (Conepatus chingue), el gato montés (Felis pajero), la chilla (Dusicyon griseus) y un marsupial, la yaca (Marmosa elegans).

En cuanto a la vegetación y de acuerdo con la fisonomía, las comunidades vegetales pueden agruparse en las siguientes formaciones (Figuras 4 y 5):

PUYALES: Son comunidades semidesérticas que crecen en laderas de exposición norte: Sus principales componentes son el chagual (Puya berteroniana), el quisco (Trichocereus chilensis), que crecen aproximadamente hasta los 1.000 m.s.n.m. y el chagual chico (Puya violacea) que los reemplaza a mayor altitud.

MATORRALES: Formados por arbustos altos y densos. En laderas de exposición norte crecen el tebo (Trevoa trinervis) y el colliguay (Colliguaja odorifera). Es abundante igualmente el romero (Baccharis linearis) y el coligüe (Chusquea cummingii) (QUINTANILLA,1983). 
ESTEPA ARBUSTIVA: Por encima de los 1.600 m.s.n.m., en la cumbre de los cerros más altos, se desarrolla una estepa arbustiva de altura con hierba blanca (Chuquiraga oppositifolia), neneo (Mulinum spinosum) y otros subarbustos de altura.

BOSQUES ESCLEROFILOS: Hasta los 1.000 metros de altitud son abundantes los bosques de árboles esclerófilos como el peumo (Cryptocaria alba), el boldo (Peumus boldus), el quillay (Quillaja saponaria), el molle (Schinus latifolius) y el litre (Litrhea caustica).

BOSQUES HIGROFITOS: en el fondo de quebradas en exposición sur o a orillas de las corrientes de agua crecen árboles higrófilos como la patagua (Crynodendron patagua), el canelo (Drimys winteri), el palo santo (Dasyphyllum excelsum), el lingue (Persea lingue), el belloto del norte (Beilschmiedia miersii) y el chequén (Myrceugenella chequen), entre los principales.

BOSQUE DECIDUO: Por encima de los 900 m.s.n.m. en laderas de exposịción meridional se mantiene el bosque deciduo de robles (Nothofagus obliqua var. macrocarpa). Esta formación se encuentra en su límite norte de distribución y representa un islote geográfico o una isla continental, donde se está produciendo variación y especiación de algunos de sus elementos.

ESPINALES: En los valles y sectores de piedemonte crecen comunidades arbustivas de talla arbórea espinosa con dominio del espino (Acacia caven) que reemplazaron a las formaciones boscosas y de matorrales que han sido desmontadas por el hombre (QUINTANILLA,1983).

PALMARES: Se caracterizan por la dominancia de la palma de coquitos (Jubaea chilensis). Representa una vegetación tropical muy antigua que está restringida a lugares con condiciones ecológicas especiales como es el valle de Ocoa en el Parque. Corresponde a su vez al límite austral de los palmares en el globo.

\section{Los ecosistemas del Parque en el Valle de Ocoa}

Las vertientes septentrionales del macizo La Campana, en donde son muy representativas las agrupaciones de palmares, tipifican nuestra área principal de estudio por cuanto estas son las laderas de mayor sensibilidad ecológica y sobre todo más vulnerables al fuego en todo el parque.

Los palmares constituyen una reliquia, ya que las otras especies que habían acompañado al bosque de palmas habrían desaparecido. Hoy día ocupa sec- 


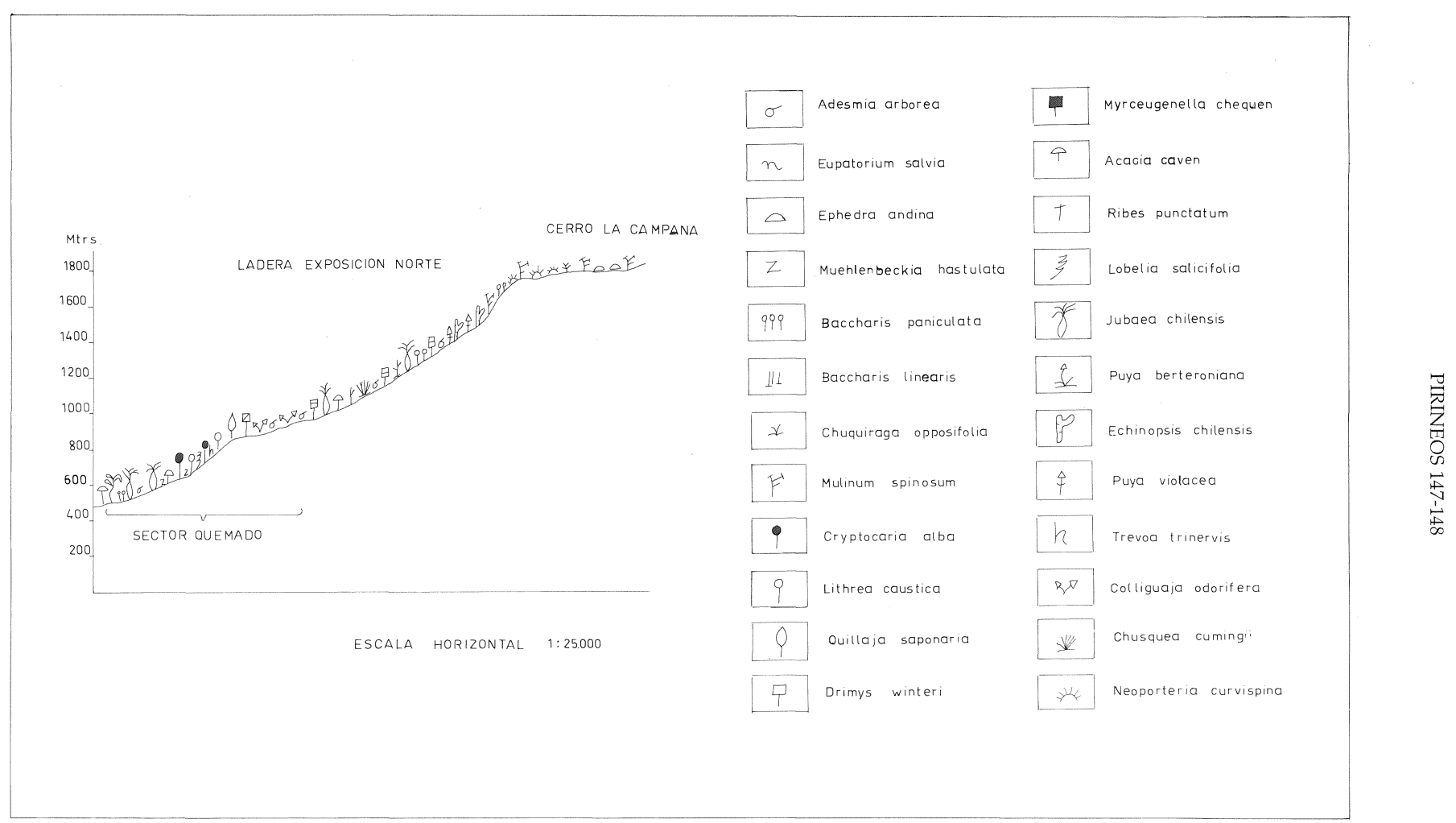

Fig. 4. Vegetación de la ladera norte del Macizo La Campana

Vegetation of the north-looking slope of Macizo La Campana 


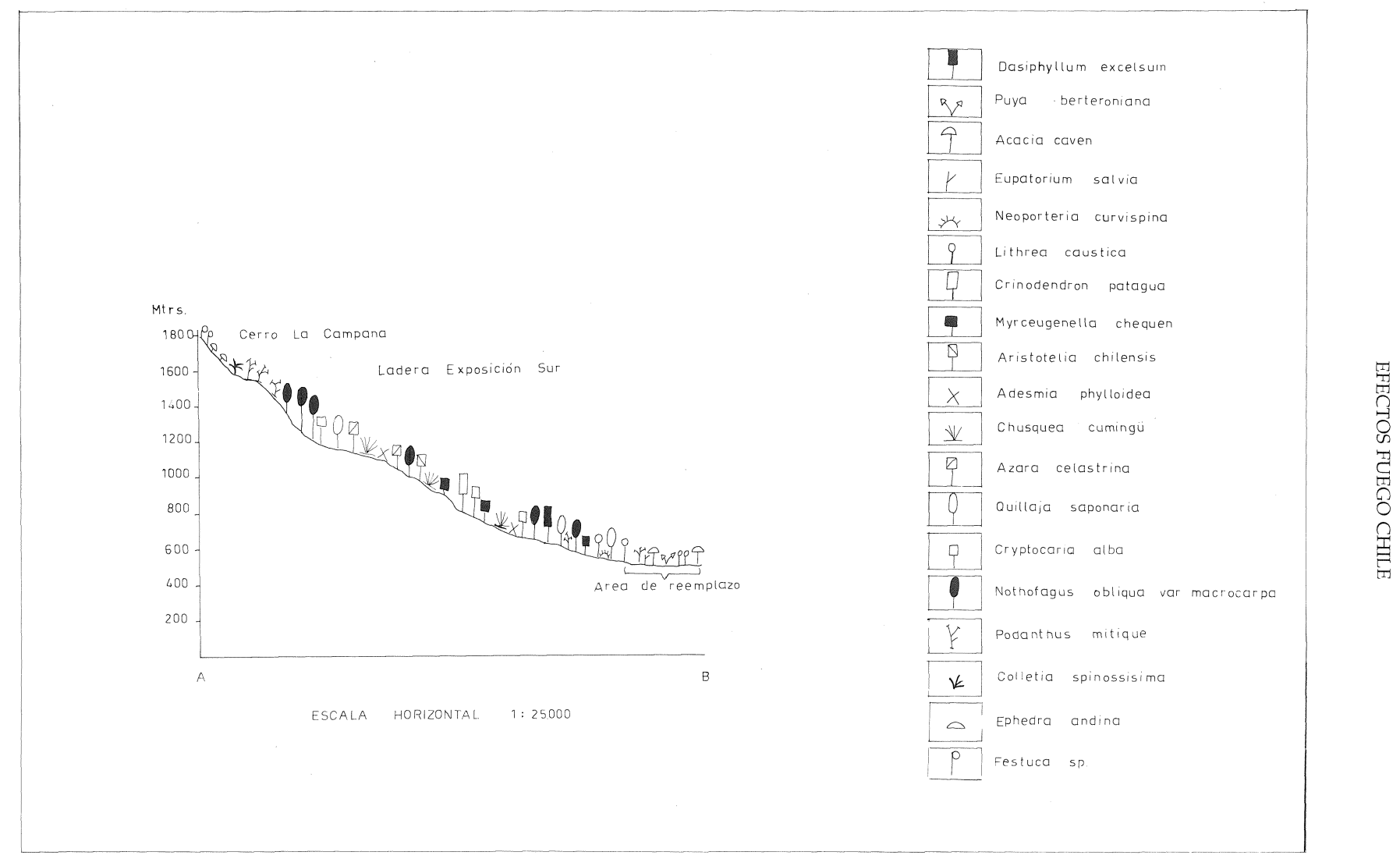

Fig. 5. Vegetación de la ladera sur del Macizo La Campana Vegetation of the south-looking slope of Macizo La Campana 
tores restringidos y en sus hábitats se mezcla con representantes de todas las formaciones vegetales que se encuentran en el parque, excepto con el bosque higrófito de Nothofagus (QUINTANILLA,1975). Evidentemente en siglos anteriores su área de distribución fue aquí más vasta.

En estos momentos Jubaea chilensis está restringida a un angosto cinturón a lo largo de líneas costeras de Chile central, desde la cuenca del río Petorca ( $32^{\circ} 35^{\prime \prime}$ sur) hasta la cuenca del río Maule por el sur ( $35^{\circ}$ sur). Hoy día a excepción de localidades como Ocoa, Cocalán, Hierro Viejo, El Salto y Rodelillo en la parte alta de Viña del Mar, no quedan grandes palmares.

$\mathrm{Al}$ interior de nuestro sector de estudio estas comunidades se hallan principalmente localizadas en tres pequeños valles en Ocoa. Además algunas especies aisladas o en pequeños grupos suelen encontrarse en la parte alta del Cajón de San Pedro (1200 ms.n.m.), en el Cajón Grande sector Granizo (1.000 m.s.n.m.) y en las Palmas de Quebrada de Alvarado. A la palma es posible localizarla hasta los 1.500-1.600 m.s.n.m. tanto en laderas como en fondos de quebradas. Se desarrollan en laderas norte, sureste u oeste en sectores a sotavento o barlovento. Lo anterior lleva a pensar que los factores que inciden en la localización de los palmares son de carácter paleoclimático y de allí su carácter de reliquia, aunque no pueden explicar las razones actuales de su distribución. El único carácter común que presentan los palmares de hoy día, al igual que en los sectores El Salto y Santos Ossa (Valparaíso y Viña del Mar), es el tipo de suelo granítico (Figura 6).

La eliminación de la mayoría de las palmas chilenas es el resultado de la cosecha de los árboles para elaborar la miel de palma, una savia azucarada que la palma produce en abundancia. Durante los siglos XVIII y XIX, cuando las palmas abastecían de azúcar a gran parte del país, se produjo una gran tala de ellas. La especie alcanza alturas entre los 12 y 18 metros con más de un metro de diámetro. Los troncos de las palmas caídas producen savia por varios meses hasta un total de 350 a 400 litros cada una. La producción de miel de palma ha continuado hasta ahora, produciéndose en la última década la tala de unas 100 unidades. Se calcula que el número de palmas existentes en Ocoa supera los 4.000 individuos.

El empobrecimiento de estos conjuntos forestales también se ha debido al pastoreo de cabras, ovejas y ganado vacuno, y al corte de ramas y cogollos en fiestas religiosas. Aunque estaba prohibida la elaboración de la miel de palma en los siglos anteriores, se mantuvo en forma clandestina por la presión de los grandes propietarios de las haciendas en que había palmares. Este proceso de extinción se aceleró aún más en el siglo XIX con la subdivisión de las estancias particularmente en Caleu, Alvarado y La Dormida. La subdivisión de la propiedad de estas tierras de pobre rendimiento y con relieve acci- 


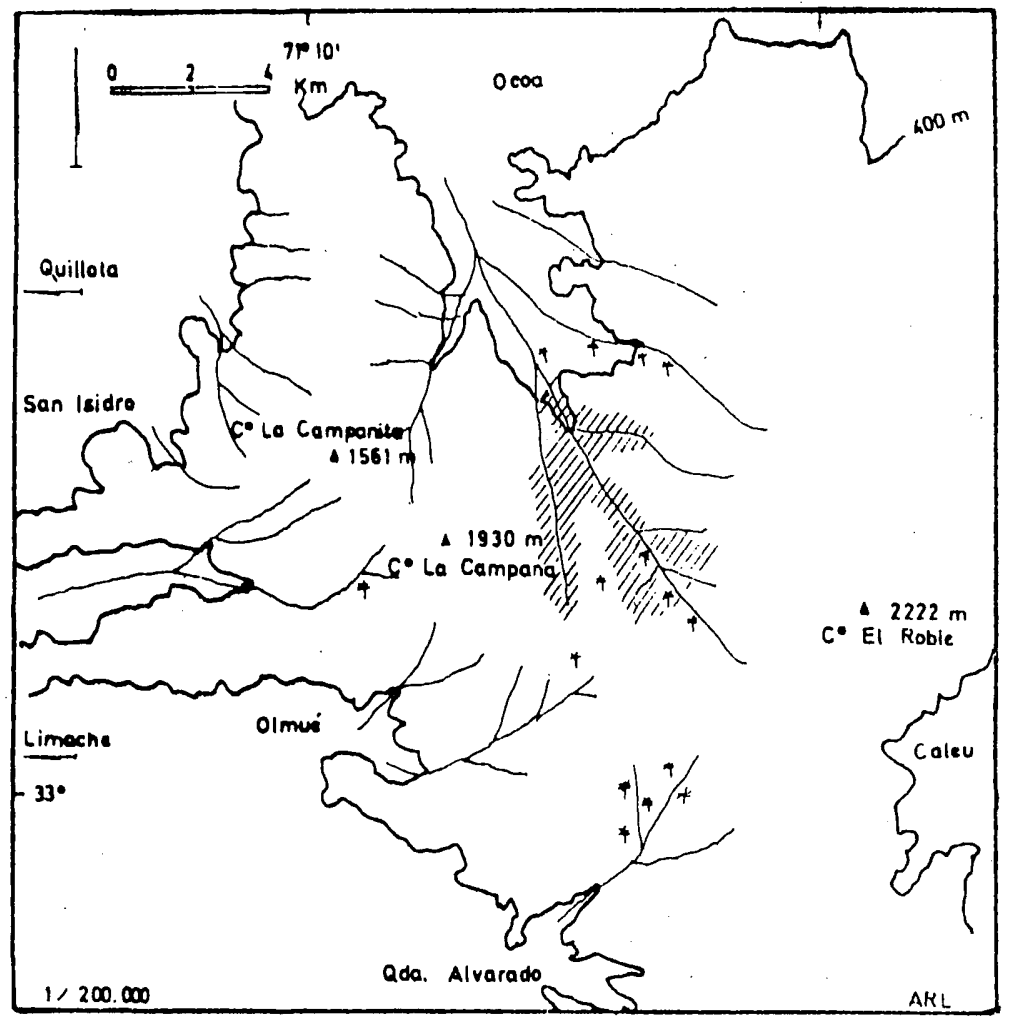

WIIID palmares

- palmas aisladas

Fig. 6. Localización de los palmares en el área de estudio Situation of palm forests on the study area

dentado favoreció la demanda de pequeños propietarios ante las autoridades para que les autorizaran la corta y elaboración de la miel (CU்NILL,1974).

Hoy día los palmares continúan bajo una fuerte presión antrópica, sobre todo por los incendios forestales, debido a que se queman ramas de aquellas palmas que se consideran secas afectando la producción de los frutos. También el ganado sigue presente, a pesar de que ha disminuído su proporción, y la búsqueda de leña en los arbustos de su sotobosque afecta a la formación. De igual forma la explotación de la miel implica la tala de otras especies nativas tales como el peumo (Cryptocaria alba), el canelo (Drimys winteri) , el boldo (Peumus boldus) y otras especies (Figura 7). 


\section{El fuego en los ecosistemas del Parque Nacional La Campana}

El fuego ha sido también un componente habitual en el cambio de los paisajes de Chile y particularmente en su zona mediterránea, aunque aquí no existen plantas pirófitas como en otros medios similares (TRABAUD, 1981).

En este siglo los incendios ocurridos en el país han ocasionado mayor impacto por su cercanía y riesgos a los asentamientos humanos y sus obras. Casi todos corresponden al tipo de fuego superficial y son originados por actividades humanas.

Entre los $32^{\circ}$ y $37^{\circ}$ sur se encuentran los principales focos de fuego de vegetación de Chile en estas últimas tres décadas, produciéndose fundamentalmente entre fines de primavera y todo el verano. Por ejemplo, en la temporada 1989-1990 se censaron 2710 incendios en el país y el 40\% se detectaron en la región de Valparaíso (la V Región administrativa del país) y la mayoría de ellos correspondió a acciones de las poblaciones de marginalidad periurbana en directa relación con el uso energético del medio circundante (Figura 8).

Sucesivos incendios se han producido en las laderas del cordón montañoso del cerro La Campana. Entre el 19 y 25 de febrero de 1984 ocurrió un gran incendio en el Parque, comprometiendo 310 hectáreas de bosque esclerófilo, 580 hectáreas de matorrales esclerófilos y formaciones xéricas y 60 hectáreas de pastizales, las que en conjunto representan el 17\% del área del sec-

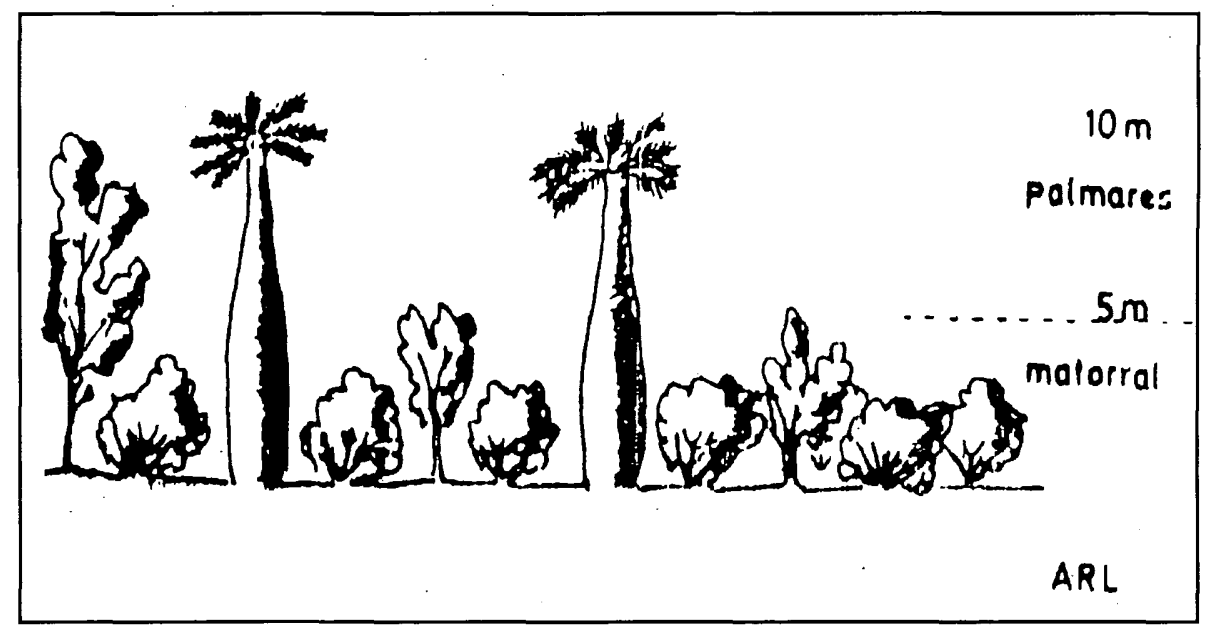

Fig. 7. Estratificación en los bosques de palmeras Vertical structure of palm forests 


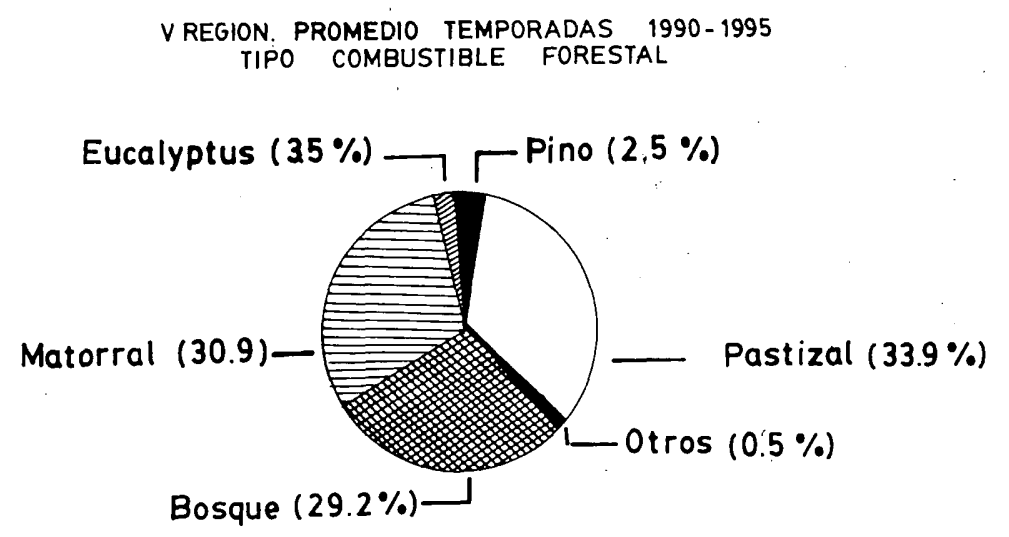

Fig. 8. Distribución en porcentaje de las comunidades quemadas en los años 1990-1995 Distribution of burned formations during the 1990-1995 wildfires

tor Ocoa del Parque (SAIZ,1990). En febrero de 1996 se quemaron 60 hectáreas de matorrales y pastizales, nuevamente en esta área.

El interés por el estudio de los incendios de vegetación en esta zona se acentúa por la presencia, entre las formaciones vegetales, de palmares de Jubaea chilensis, única especie de palmera en Chile como ya va dicho y cuyas poblaciones están en franco retroceso (GUERRA,1979).

Estudios realizados durante 4 años por especialistas de universidades de Valparaíso (VILLASEÑOR et al., 1986, SAIZ \& VILLASEÑOR, 1990) sobre la regeneración de las plantas demostraron modificaciones evidentes en los ecosistemas del parque por impacto del fuego. Se comprobó por ejemplo un cambio en la estructura fisonómica del bosque por cuanto sus especies al rebrotar, lo hacen en forma de arbustos lo que transforma a la comunidad en matorral.

Nosotros pudimos observar la situación en que subsisten comunidades resistentes al fuego como Cryptocaria alba y Lithrea caustica árboles esclerófilos de recuperación vegetativa solamente. Esta última especie es el árbol que mejor responde a los incendios, junto con los arbustos xéricos, lo que avalaría la hipótesis de los especialistas anteriormente citados, y otros, en el sentido de que la estructura vegetal actual de la zona mediterránea chilena estaría modelada en buena parte, por la recurrencia de los incendios. La recuperación de otros árboles esclerófilos y arbustos se ve afectada por la fuerte herbivoría a que son sometidos sus rebrotes por parte del ganado vacuno, que generalmente se asocia a estas comunidades, y por la recolecta de los restos quemados que suele hacer gente modesta. 
Sin embargo existen especies llamadas pioneras, lo cual pudimos comprobar 8 semanas después al recorrer el lugar después del último incendio en el macizo de La Campana. Concordando con otros autores (AVILA et al. 1981) observamos aquí que el quilo (Muelenbeckia hastulata) y el romerillo (Baccharis linearis) tienden a colonizar los espacios dejados abiertos por el fuego.

En cuanto al matorral esclerófilo, se observa en Chile central que al cabo de un año del fuego se producen cambios en la riqueza, abundancia y diversidad de las especies herbáceas, fundamentalmente de las anuales. Inmediatamente después del fuego se produce una gran colonización de lugares abiertos por parte de las hịerbas anuales, con un importantísimo incremento de un $30 \%$ en el número de especies respecto a sectores no quemados (SAIZ \&VILLASEÑOR,1990; ARMESTO et al.,1985).

En cuanto a las herbáceas perennes, el efecto es inicialmente negativo al no ser favorecida la colonización por medio de ellas.

En conclusión, se observa que a largo plazo se produce una pérdida de las especies menos frecuentes, lo que podría significar una tendencia a una estabilidad tanto en riqueza específica como en los estadios no quemados.

En cuanto a otro tipo de daños al ecosistema de estas montañas, hacemos referencia a procesos erosivos. Estos aún no se han medido ni seguido regularmente, pero ya se puede hablar deque se detecta una erosión leve y de tipo laminar y que avanza de manera persistente, sobre todo en las laderas de exposición norte donde predomina un matorral esclerófilo abierto y muy alterado.

En la mayoría de las vertientes del valle de Ocoa los efectos dél fuego han aclarado el estrato arbustivo y herbáceo posibilitändo con mayor frecuencia el desmenuzamiento del-suelo én sectores con pendientes superiores a los $35^{\circ}$ ÿën lös espacios que han quedado abiertos hasta el inicio de las lluvias, cuando comienza un rebrote o germinación de las especies postincendio. Por otra parte, la presencia de ganado vacuno que se desplaza aún en lugares abruptos contribuye igualmente a acelerar la pérdida del suelo coadyuvado por la gran cantidad de madrigueras de varios roedores presentes en el parque. Así, ante eventuales nuevos incendios de superficie o de suelo en las comunidades vegetales, y si se continúa permitiendo el desplazamiento de ganado en el Parque sobre todo en los sectores de fuertes pendientes, parece improbable que se desencadenen procesos erosivos hasta llegar a generar algunos tipos de deslizamientos desde los 1.600-1.800 metros durante las lluvias intempestivas y violentas que suelen sucederse en algunos inviernos, como ocurrió durante el de 1991.

Los estudios realizados por los especialistas antes citados con respecto a la recuperación de comunidades vegetales, demostraron que después de dos años de producido el incendio, la cobertura vegetal no varió significativa- 


\section{EFECTOS FUEGO CHILE}

mente, aunque ello sí ocurrió con el porcentaje de especies que conforman las comunidades arbustivas.

El tebo (Trevoa trinervis) y el quilo (Muelenbeckia hastulata) durante los 4 años siguentes al incendio fueron aumentando notoriamente. Ello fue paralelo de la reducción del porcentaje de cobertura de dos árboles típicos esclerófilos de la región como son el litre (Litrhea caustica) y el quillay (Quillaja saponaria). El aumento real de la cobertura ocurre durante el tercer año, estableciéndose el dominio de especies rebrotadas, principalmente litre, y la disminución porcentual de especies invasoras como tebo y quilo (SAIZ \& VILLASEÑOR,1990; ARMESTO et al., 1978).

También nosotros observamos comunidades resistentes al fuego: por ejemplo la de Lithrea caustica y Cryptocaria alba, árboles que muestran recuperación vegetativa solamente; la de los arbustos Adesmia arborea y Colliguaja odorifera, los cuales rebrotan rápidamente y durante el mismo año ya llegan a florecer.

Al recuperarse las plantas arbóreas y arbustivas después del incendio, se observa que lo hacen con crećimiento simpodial, lo que les da el aspecto de arbustos y al conjunto el de matorral como hemos adellantado. Por ello nosotros en este caso nominamos a la agrupación como un matorral esclerófilo. No se sabe en cuánto tiempo este matorral puede recuperar su estructura y fisonomía de bosque, aunque de acuerdo con Villaseñor y Saíz (op. cit.), por la relación entre el tiempo ( 2 años) y la altura alcanzada no puede ser inferior a 10-15 años.

cendios, junto con

El litre es la especie arbórea que mejor responde a los incendios, junto con
arbustos xéricos, lo que avalaría la hipótesis de ecólogos y botánicos nacionales con respecto a que la estructura vegetal actual de la zona mediterránea chilena estaría modelada por la recurrencia de los incendios forestales, junto a otras acciones del hombre sobre el medio.

Entre las especies de Chile central, el espino (Acacia caven) y el litre son las que inician el rebrote en menor tiempo después del fuego; en algunos individuos se observaron rebrotes antes de las 3 semanas. Otras especies como el quillay o el peumo requieren más tiempo. Como ya señalamos antes por la acción intensa del ganado vacuno sobre sus rebotes.

\section{Conclusiones}

Se han hecho observaciones sobre el terreno para atisbar los cambios y sus efectos en el ecosistema, que han producido los llamados incendios forestales en las formaciones vegetales de un macizo de la cordillera central de Chile, en las cadenas costeras. 
Se comprueba que en la vertiente oriental del Macizo de La Campana, el bosque esclerófilo va derivando a un estado de matorral como consecuencia fundamentalmente del rebrote de las plantas en condiciones de postincendio, en tanto que hay comunidades resistentes al fuego tanto en el bosque como en las comunidades arbustivas de carácter xérico. Es probable y sobre todo de no producirse nuevos fuegos, que este matorral pueda recuperar en un tiempo de 12 a 15 años su fisonomía de bosque esclerófilo, aunque rebajando su altura. Hasta ahora los incendios no han afectado de manera importante a las comunidades de las palmeras más australes del mundo [Jubaea chilensis Mol.(Baillon)].

Gran parte del macizo corresponde a una zona de Parque nacional en la cual ha habido incendios en cuatro ocasiones en esta última década, siendo el útimo en febrero de 1996, el cual quemó 45 hectáreas de vegetación nativa. Los componentes esclerófilos del bosque, después que se queman, en gran parte logran ir regenerándose especialmente Lithrea caustica, árbol que por su toxicidad los herbívoros no comen sus rebrotes.

Las laderas de exposición norte del macizo, fundamentalmente acantonadas en el denominado valle de Ocoa, por encima de los 700 m.s.n.m. poseen pendientes entre $25 \%$ y $35 \%$ y la pérdida de vegetación arbustiva y subarbustiva por el fuego es considerable, favoreciendo en consecuencia la puesta en marcha de procesos erosivos, los cuales hasta ahora los caracterizamos como de erosión laminar y superficial. Sin embargo, estos procesos no sólo pueden ir avanzando a causa de las lluvias (las que durante los inviernos lluviosos alcanzan aquí a valores cercanos a los $800 \mathrm{~mm}$ ) y la eventualidad de nuevos incendios en el pastizal y el matorral, sino a causa del pisoteo del ganado que sube a bastante altura en estas laderas en busca de alimento más fresco, y de la abundancia de madrigueras que van soltando el suelo. Confiamos en ir observando estos procesos en el futuro.

\section{Referencias}

ARAYA S. \& AVILA, G., 1981.: Rebrote de arbustos afectados por el fuego en el matorral chileno. An. Museo Hist. Nat. Valparaíso, 14 .

ARMESTO J. \& GUTIÉRREZ, J., 1978: El efecto del fuego en la estructura de la vegetación de Chile Central. An. Museo Hist. Nat. Valparaíso, 11.

ARMESTO J. \& PICKETT. S., 1985: A mechanistic approach to the study of succession in the Chilean matorral. Revista Chilena de Historia Natural, 58 .

AVILA G., ALJARO M. \& SILVA B., 1981: Observaciones en el estrato herbáceo del matorral después del fuego. An. Museo Hist. Nat. Valparaíso,14. 
AVILA G., ALJARO, M. \& MONTENEGRO, G., 1990: Incendios en la vegetación mediterránea. In: FUENTES Y PRENAFRETA (Eds.): Ecología del paisaje. de Chile central. Ed. Univ. Católica de Chile.

CUNILL, P., 1974: Geografía del deterioro del paisaje chileno. In: Ecología, ciencia básica para la supervivencia del hombre. Ediciones Universitarias de Valparaíso.

GUERRA G., HEPP A. \& BASCUR F., 1979: Mapa de combustibilidad de la V Región de Chile. Ciencias Forestales 1(3)

INE (Inst. Nac. Estadísticas), 1990: Estadísticas del medio ambiente en Chile. 220 pp. Santiago.

QUINTANILLA, V., 1975: La carta bioclimática de Chile Central. Revista Geográfica de Valparaíso, 5. Universidad Católica de Valparaíso.

QUINTANILLA V., 1976: Biogeografía de la V Región de Chile. Rev. Geográfica de Valparaíso, 6.

QUINTANILLA V., 1979: Létagement altitudinal de la végétation au Chili central. Les profils phytogéographiques. Biogeographica, 16 .

QUINTANILLA, V., 1983: Biogeografía de Chile. 232 pp. Col Geografía de Chile. Ediciones del Instituto Geográfico Militar, Santiago.

QUINTANILLA, V., 1995: Estudio de caso de efectos de los incendios en la vegetación esclerófila de Chile mediterráneo. Anales XVI Congreso Nacional de Geografía. Valdivia.

RODRÍGUEZ, A., 1980: Formaciones vegetales del Parque Nacional La Campana. Tesis de geógrafo, Universidad Católica de Valparaíso.

SAIZ, F. \& VILLASEÑOR, R., 1990: Los incendios forestales en el Parque Nacional La Campana, sector Ocoa. Efecto sobre el estrato arbustivo arbóreo. Anales Museo Historia Natural de Valparaíso , 21.

TRABAUD, L., 1981.: Man and fire impacts on mediterranean vegetation. In: F. DI CASTRI et al. (Eds.): Mediterranean-type shrublands (Ecosystems of the world II) : 523-537. Elsevier.

VILLASEÑOR, R., SAIZ, F. \& BUSTAMANTE, P .1986. Impacto de los incendios forestales en el ambiente de la V región de Chile. Proc. II Encuentro Nacional del medio ambiente. CPIMA. vol 1. Talca. 